\title{
Author Correction: Imaging low-mass planets within the habitable zone of $\alpha$ Centauri
}

\author{
K. Wagner (1), A. Boehle (D), P. Pathak (1), M. Kasper, R. Arsenault, G. Jakob, U. Käufl (1), S. Leveratto, A.-L. Maire, \\ E. Pantin, R. Siebenmorgen (1), G. Zins, O. Absil (1), N. Ageorges, D. Apai, A. Carlotti, É. Choquet (1), C. Delacroix (D), \\ K. Dohlen (1D, P. Duhoux, P. Forsberg, E. Fuenteseca, S. Gutruf, O. Guyon, E. Huby, D. Kampf, M. Karlsson (D), \\ P. Kervella (D), J.-P. Kirchbauer, P. Klupar, J. Kolb, D. Mawet, M. N’Diaye (D), G. Orban de Xivry (D), S. P. Quanz (D), \\ A. Reutlinger, G. Ruane, M. Riquelme, C. Soenke, M. Sterzik $\mathbb{D}$, A. Vigan $\mathbb{D} \&$ T. de Zeeuw
}

Correction to: Nature Communications https://doi.org/10.1038/s41467-021-21176-6, published online 10 February 2021.

The original version of this Article contained an error in Fig. 1b, in which the units incorrectly read 'AU,' instead of the correct 'au'. This has been corrected in both the PDF and HTML versions of the Article.

The original version of this Article contained an error in Fig. 1b. In the original version of Fig. 1b, astronomical unit was considered instead of arc seconds, which results in a factor of about 1.3 in the values of 'periastron', 'maximum stable orbit' and the 'semi-major axis (a)' of the system. In the original version of Fig. 1b, 'periastron' incorrectly read '8.6 AU' instead of the correct '11.3 au', 'maximum stable orbit' incorrectly read ' $\sim 2.8 \mathrm{AU}$ ' instead of the correct ' $\sim 3.8 \mathrm{AU}$ ', 'semi major axis (a)' incorrectly read '17.6 $\pm 0.1 \mathrm{AU}$ ' instead of the correct ' $23.6 \pm 0.1$ au'. This information is ancillary; the results are not affected. This has been corrected in both the PDF and HTML versions of the Article.

Published online: 05 May 2021 \footnotetext{
reproduction in any medium or format, as long as you give appropriate credit to the original author(s) and the source, provide a link to the Creative Commons license, and indicate if changes were made. The images or other third party material in this article are included in the article's Creative Commons license, unless indicated otherwise in a credit line to the material. If material is not included in the article's Creative Commons license and your intended use is not permitted by statutory regulation or exceeds the permitted use, you will need to obtain permission directly from the copyright holder. To view a copy of this license, visit http://creativecommons.org/licenses/by/4.0/.
}

(c) Open Access This article is licensed under a Creative Commons Attribution 4.0 International License, which permits use, sharing, adaptation, distribution an

(c) The Author(s) 2021 